\title{
Conhecimentos, práticas e atitudes de médicos e enfermeiros sobre saúde bucal na puericultura na APS
}

\author{
Oral health knowledge, attitudes, and practices of doctors and \\ nurses in the PHC of children
}

\author{
Mariana Loch dos Reis* \\ Idiana Rita Luvison ${ }^{* *}$ \\ Daniel Demétrio Faustino-Silva**
}

\section{Resumo}

Objetivo: investigar os conhecimentos, as práticas e atitudes em saúde bucal na puericultura de médicos e enfermeiros, contratados e residentes do Serviço de Saúde Comunitária do Grupo Hospitalar Conceição (SSC-GHC). Sujeitos e método: aplicação de um questionário fechado, com 32 questões de múltipla escolha, elaborado pelos pesquisadores, para avaliar os conhecimentos, as práticas e as atitudes (CAP) em saúde bucal na puericultura de médicos e enfermeiros, contratados e residentes, de onze das doze unidades de saúde que compõem o SSC-GHC. A amostra intencional foi composta por 47 médicos e 27 enfermeiros. Os dados foram tabulados e analisados com auxílio do software SPSS, por meio do teste Qui-Quadrado e teste $t$, ao nível de significância estatística de $p<0,05$. Resultados: os resultados obtidos mostram que há pouca diferença estatisticamente significativa entre os conhecimentos, práticas e atitudes de médicos e enfermeiros do SSC-GHC, inclusive em relação ao tempo de formação/ prática profissional. Conclusão: ainda há desconhecimento de muitos em relação a alguns pontos sobre a saúde bucal na puericultura, necessitando de ações de educação permanentes sobre o tema.

Palavras-chave: Saúde bucal. Cuidado da criança. Atenção primária à saúde. Médicos de família. Enfermeiras de Saúde da Família.

\section{Introdução}

Os cuidados com a saúde bucal do futuro bebê devem começar no período pré-natal, momento em que a gestante está mais aberta a receber as informações referentes à saúde do filho ${ }^{1}$. Consultas odontológicas da gestante no período pré-natal são momentos propícios para educação em saúde bucal da mãe e do futuro bebê ${ }^{2}$. Nesse sentido, serviços de atenção primária à saúde têm preconizado a inserção da saúde bucal nos cuidados da gestante, como ocorre na cidade de Curitiba e no Serviço de Saúde Comunitária do Grupo Hospitalar Conceição, em Porto Alegre ${ }^{3,4}$.

Após o nascimento, as consultas passam a ser específicas para acompanhar o desenvolvimento do bebê (consultas de puericultura), realizadas geralmente por médicos e enfermeiros. O SSC-GHC considera atendimento em puericultura o período compreendido entre zero e doze anos, entretanto, o foco da atenção é no primeiro ano de vida da criança. Já o presente trabalho aplica o termo puericultura para se referir ao primeiro ano de vida. Nesse período as consultas devem tratar sobre os diferentes temas que envolvem os cuidados com o bebê e o seu desenvolvimento. 
No SSC-GHC, utiliza-se o protocolo Atenção à saúde da criança de 0 a 12 anos $^{4}$, como um guia profissional no desenvolvimento de ações voltadas para a atenção integral da saúde da criança nos seus primeiros anos de vida. Nesse protocolo estão incluídas as informações sobre saúde bucal que devem ser transmitidas aos pais pelo médico e/ou enfermeiro responsável pelas consultas de puericultura.

Tendo em vista a importância do cuidado precoce, o SSC-GHC usa como indicador da atenção à saúde bucal da criança o mínimo de uma consulta odontológica entre zero e doze meses do bebê, ocasionando encaminhamentos precoces a equipe de saúde bucal. Muitas crianças vêm à consulta odontológica ainda sem dentes, para que os pais conheçam os hábitos alimentares saudáveis, a importância da higiene bucal do bebê e como fazê-la, os hábitos de sucção deletérios (dedo e chupeta) e a importância do aleitamento materno, além de nutricional e afetiva, para o melhor desenvolvimento e crescimento dos músculos e dos ossos faciais, ou seja, um volume grande de informações para as mães, que muitas vezes não veem sentido, pois seus filhos sequer apresentaram os primeiros dentes.

As ações de cuidado no primeiro ano de vida devem ser realizadas de forma multidisciplinar, evitando-se criar programas de saúde bucal específicos para esse grupo etário, de modo que não ocorra de forma vertical e isolada da área médico-enfermagem $^{5}$. Orientações sobre saúde bucal infantil não são tarefa unicamente do cirurgião-dentista, mas de todos que atendem mães e crianças ${ }^{6}$.

Todos os membros que compõem as equipes de saúde, quando capacitados, podem orientar os pais e/ou responsáveis pelas crianças acerca dos cuidados bucais na primeira infância. Portanto, não parece imprescindível uma consulta com o cirurgião-dentista nesse momento, pois não são aspectos exclusivos do núcleo de odontologia; são aspectos transversais aos núcleos de medicina, enfermagem, nutrição e odontologia, e que precisam ser reforçados a cada consulta com todos os profissionais da equipe. Essas orientações podem ser dadas nas consultas de puericultura, não necessitando de um horário exclusivo com o cirurgião-dentista. A partir dos seis meses de idade, quando, geralmente, o primeiro dente erupciona, é interessante levar o bebê à consulta com o dentista, para que se possa acompanhar o aparecimento dos dentes e reforçar as informações dadas nas consultas de puericultura anteriores. Acredita-se que ao nascerem os dentes, aumente o interesse dos pais pela saúde bucal da criança.

O objetivo deste estudo foi investigar os conhecimentos, as práticas e as atitudes em saúde bucal nas ações de puericultura de médicos e enfermeiros contratados e residentes do Serviço de Saúde Comunitária do Grupo Hospitalar Conceição, no município de Porto Alegre, RS.

\section{Materiais e método}

O estudo foi do tipo quantitativo analítico transversal e visou à exploração dos conhecimentos dos médicos e enfermeiros sobre saúde bucal na puericultura. Foi aplicado um questionário fechado, com 32 questões de múltipla escolha, elaborado pelos pesquisadores, para avaliar os conhecimentos, as práticas e atitudes em saúde bucal no campo da puericultura de médicos e enfermeiros contratados e residentes, de onze das doze unidades de saúde que compõem o SSC-GHC. A amostra intencional foi composta por 47 médicos e 27 enfermeiros que aceitaram participar do estudo. Esse instrumento para profissionais de saúde foi adaptado a partir de um CAP voltado a pais ou responsáveis ${ }^{7}$. O instrumento CAP do presente estudo é composto por perguntas objetivas de escolha simples entre cinco alternativas, com níveis de concordância total, parcial ou neutra, divididas em três blocos. O bloco A, composto por doze questões, refere-se aos conhecimentos sobre saúde bucal na primeira infância adquiridos pelos profissionais durante sua formação e ao longo da carreira, abordando assuntos gerais sobre alimentação, higiene bucal e cáries. O bloco $B$, composto por treze questões, refere-se às atitudes sobre saúde bucal na primeira infância, sobre aquilo que os profissionais compreendem do tema e orientam na sua rotina de consultas. O bloco C, composto por sete questões, refere-se às práticas profissionais sobre saúde bucal na primeira infância, ou seja, sobre o que de fato eles recomendam aos pais/ responsáveis referente à higiene bucal, nascimento dos dentes e consulta com dentista.

Os dados foram tabulados e analisados com auxílio do software SPSS versão 16.0, por meio do teste Qui-Quadrado e teste t, ao nível de significância estatística de $\mathrm{p}<0,05$. O trabalho foi aprovado pelo Comitê de Ética em Pesquisa do GHC (CAAE: 26898314.9.0000.5530 e CEP: 14-007).

\section{Resultados}

Foram convidados 150 profissionais para participar da pesquisa, obtendo-se um retorno de 74 deles, sendo $47(63,5 \%)$ médicos e $27(36,5 \%)$ enfermeiros. Ocorreu a exclusão de 76 indivíduos devido à falta de interesse em participar da pesquisa, ao afastamento do trabalho ou ao trancamento da residência no período de coleta dos dados. Dos incluídos, $44(59,5 \%)$ eram do sexo feminino e trinta $(40,5 \%)$ do sexo masculino. O tempo de formado variou de um a 35 anos, com média de 16,63 anos.

Na Tabela 1, o número de acertos em cada questão por categoria profissional mostra que não houve diferença estatisticamente significativa entre médicos e enfermeiros. As questões que tiveram um bom número de acerto compreendiam os temas: primeira consulta com o dentista, benefícios do aleitamen- 
to materno, acréscimo de açúcar na mamadeira, mamada noturna, consumo de água, resistência à higiene bucal, saúde bucal na formação, saúde bucal nas consultas de puericultura, equipe de saúde bucal detém o conhecimento de saúde bucal, como realizar a higiene bucal; enquanto as questões sobre aleitamento materno prolongado, fórmulas, frequência de recomendação da higiene bucal, qual pasta de dente recomendada, tiveram baixo índice de acertos.

Tabela 1 - Número de acertos em cada questão por categoria profissional, SSC-GHC, Porto Alegre-RS, 2014

\begin{tabular}{|c|c|c|c|}
\hline \multirow{3}{*}{ Questão } & \multicolumn{2}{|c|}{ Categoria profissional } & \multirow{3}{*}{$\mathrm{p}^{*}$} \\
\hline & \multirow{2}{*}{$\begin{array}{c}\text { Médicos } \\
\text { no (\%) acertos }\end{array}$} & \multirow{2}{*}{$\begin{array}{c}\text { Enfermeiros } \\
\mathrm{n}^{\circ}(\%) \text { acertos }\end{array}$} & \\
\hline & & & \\
\hline Cárie em menores de 1 ano & $29(61,7)$ & $15(57,7)$ & 0,785 \\
\hline Dentes de leite nascem com cáries & $12(25,5)$ & $11(40,7)$ & 0,271 \\
\hline Tratamento dentes de leite & $31(66,0)$ & $17(63,0)$ & 0,995 \\
\hline Primeira consulta com dentista & $42(89,4)$ & $23(85,2)$ & 0,716 \\
\hline Creme dental com flúor & $18(38,3)$ & $8(29,6)$ & 0,618 \\
\hline Fluorose & $17(36,2)$ & $11(40,7)$ & 0,888 \\
\hline Aleitamento materno prolongado & $3(6,4)$ & $0(0,0)$ & 0,295 \\
\hline Cárie e antibiótico & $15(25,5)$ & $8(29,6)$ & 0,912 \\
\hline Transmissibilidade bacteriana & $20(42,6)$ & $13(48,1)$ & 0,823 \\
\hline Saúde bucal materna & $14(29,8)$ & $10(37,0)$ & 0,701 \\
\hline Sucos artificiais são cariogênicos & $38(80,9)$ & $20(74,1)$ & 0,698 \\
\hline Fórmulas com açúcar & $7(14,9)$ & $2(7,4)$ & 0,472 \\
\hline Benefícios do aleitamento materno & $41(87,2)$ & $24(88,2)$ & 1,000 \\
\hline Adição de açúcar nas mamadeiras & $45(95,7)$ & $27(100,0)$ & 0,530 \\
\hline Orientação quanto ao uso de mamadeira & $44(93,6)$ & $26(96,3)$ & 1,000 \\
\hline Mamadeira noturna & $30(63,8)$ & $18(66,7)$ & 1,000 \\
\hline Consumo de água após os seis meses & $40(85,1)$ & $24(88,9)$ & 0,738 \\
\hline Resistência do bebê à higiene bucal & $44(93,6)$ & $25(92,6)$ & 1,000 \\
\hline Conhecimentos e formação & $37(78,7)$ & $18(66,7)$ & 0,386 \\
\hline Saúde bucal durante a formação & $40(85,1)$ & $21(77,8)$ & 0,529 \\
\hline Espaços de educação permanente & $20(42,6)$ & $13(48,1)$ & 0,823 \\
\hline Prática interdisciplinar & $39(83,0)$ & $19(70,4)$ & 0,330 \\
\hline Uso do protocolo da criança & $34(72,3)$ & $25(92,6)$ & 0,074 \\
\hline Orientação sobre saúde bucal & $43(91,5)$ & $25(92,6)$ & 1,000 \\
\hline Somente equipe de saúde bucal orienta & $42(89,4)$ & $26(96,3)$ & 0,406 \\
\hline Frequência da limpeza da boca & $9(19,1)$ & $8(29,6)$ & 0,456 \\
\hline Como limpar boca sem dentes & $42(89,4)$ & $23(85,2)$ & 0,716 \\
\hline Como limpar a boca com dentes & $25(53,2)$ & $17(63,0)$ & 0,567 \\
\hline Qual pasta usar com 1 ano & $1(2,1)$ & $2(7,4)$ & 0,550 \\
\hline Quantidade de pasta para 1 ano & $26(55,3)$ & $18(66,7)$ & 0,477 \\
\hline Frequência ideal de consultas & $20(42,6)$ & $17(63,0)$ & 0,147 \\
\hline Nascimento dos primeiros dentes & $28(59,6)$ & $20(74,1)$ & 0,315 \\
\hline
\end{tabular}

${ }^{*}$ teste Qui-Quadrado $(\alpha=0,05)$

Fonte: elaborado pelos autores com dados da pesquisa.

Em relação ao tempo de formado, mais ou menos do que dez anos, apenas nas questões sobre transmissibilidade das bactérias da cárie, aleitamento e mamadeira noturna, suficiência e adequação dos espaços de educação permanente do SSC-GHC, e período de nascimento dos primeiros dentes do bebê, houve diferença estatisticamente significativa, como mostra a Tabela 2. 
Tabela 2 - Número de acertos em cada questão por ano de formado, SSC-GHC, Porto Alegre-RS, 2014

\begin{tabular}{|c|c|c|c|}
\hline \multirow{3}{*}{ Questão } & \multicolumn{2}{|c|}{ Anos de formado } & \multirow{3}{*}{$\mathrm{p}$} \\
\hline & \multirow{2}{*}{$\begin{array}{c}\text { Menos de } 10 \text { anos } \\
n^{\circ}(\%) \text { acertos }\end{array}$} & \multirow{2}{*}{$\begin{array}{c}\text { Mais de } 10 \text { anos } \\
\mathrm{n}^{\circ}(\%) \text { acertos }\end{array}$} & \\
\hline & & & \\
\hline Cárie em menores de 1 ano & $14(51,9)$ & $30(65,2)$ & 0,379 \\
\hline Dentes de leite nascem com cáries & $9(33,3)$ & $14(30,4)$ & 1,000 \\
\hline Tratamento dentes de leite & $16(59,3)$ & $32(69,6)$ & 0,522 \\
\hline Primeira consulta com dentista & $22(81,5)$ & $42(31,3)$ & 0,276 \\
\hline Creme dental com flúor & $7(25,9)$ & $18(39,1)$ & 0,372 \\
\hline Fluorose & $6(22,2)$ & $21(45,7)$ & 0,080 \\
\hline Aleitamento materno prolongado & $0(0,0)$ & $3(6,5)$ & 0,291 \\
\hline Cárie e antibiótico & $5(18,1)$ & $15(32,6)$ & 0,302 \\
\hline Transmissibilidade bacteriana & $6(22,2)$ & $26(56,5)$ & $0,009 *$ \\
\hline Saúde bucal materna & $8(29,6)$ & $16(34,8)$ & 0,846 \\
\hline Sucos artificias são cariogênicos & $20(74,1)$ & $37(80,4)$ & 0,733 \\
\hline Fórmulas com açúcar & $3(11,1)$ & $6(13,0)$ & 1,000 \\
\hline Benefícios do aleitamento materno & $23(85,2)$ & $41(89,1)$ & 0,718 \\
\hline Adição de açúcar nas mamadeiras & $27(100,0)$ & $44(95,7)$ & 0,527 \\
\hline Oriento uso de mamadeira & $27(100,0)$ & $42(91,3)$ & 0,290 \\
\hline Mamadeira noturna & $11(40,7)$ & $36(78,3)$ & $0,003 *$ \\
\hline Consumo de água após os seis meses & $23(85,2)$ & $40(87,0)$ & 1,000 \\
\hline Resistência do bebê à higiene bucal & $25(92,6)$ & $43(93,5)$ & 1,000 \\
\hline Conhecimentos e formação & $18(66,7)$ & $36(78,3)$ & 0,416 \\
\hline Saúde bucal durante a formação & $22(81,5)$ & $38(82,6)$ & 1,000 \\
\hline Espaços de Educação Permanente & $17(63,0)$ & $15(32,6)$ & $0,023 *$ \\
\hline Prática interdisciplinar & $23(85,2)$ & $35(76,1)$ & 0,529 \\
\hline Uso Protocolo da Criança & $20(74,1)$ & $38(82,6)$ & 0,568 \\
\hline Orientar sobre saúde bucal & $23(85,2)$ & $44(95,7)$ & 0,185 \\
\hline Somente equipe de saúde bucal orienta & $26(96,3)$ & $41(89,1)$ & 0,403 \\
\hline Frequência da limpeza da boca & $8(29,6)$ & $9(19,6)$ & 0,487 \\
\hline Como limpar boca sem dentes & $26(96,3)$ & $39(84,8)$ & 0,244 \\
\hline Como limpar a boca com dentes & $16(59,3)$ & $26(56,5)$ & 1,000 \\
\hline Qual pasta usar com 1 ano & $1(3,7)$ & $2(4,3)$ & 1,000 \\
\hline Quantidade de pasta para 1 ano & $14(51,9)$ & $29(63,0)$ & 0,489 \\
\hline Frequência ideal de consultas & $14(51,9)$ & $22(47,8)$ & 0,929 \\
\hline Nascimento dos primeiros dentes & $22(81,5)$ & $25(54,3)$ & $0,037^{*}$ \\
\hline
\end{tabular}

" $p<0,05$ teste Qui-Quadrado

Fonte: elaborado pelos autores com dados da pequisa.

Quando separados por categoria profissional em relação ao tempo de formado, mais ou menos do que dez anos, a diferença estatisticamente significativa na questão transmissibilidade das bactérias cariogênicas manteve-se apenas para enfermeiros, enquanto que nas questões sobre aleitamento e mamadeira noturna, suficiência e adequação dos espaços de educação permanente do SSC-GHC, apenas para médicos, conforme a Tabela 3 . 
Tabela 3 - Número de acertos em cada questão por tempo de formado e por categoria profissional, SSC-GHC, Porto Alegre-RS, 2014

\begin{tabular}{|c|c|c|c|c|c|c|}
\hline \multirow{3}{*}{ Questão } & \multicolumn{3}{|c|}{ Médicos } & \multicolumn{3}{|c|}{ Enfermeiros } \\
\hline & \multirow{2}{*}{$\begin{array}{c}\begin{array}{c}\text { Menos de } 10 \\
\text { anos }\end{array} \\
\text { n (\%) acertos }\end{array}$} & \multirow{2}{*}{$\begin{array}{c}\begin{array}{c}\text { Mais de } 10 \\
\text { anos }\end{array} \\
\mathrm{n}(\%) \text { acertos }\end{array}$} & \multirow[t]{2}{*}{$p$} & $\begin{array}{c}\text { Menos de } 10 \\
\text { anos }\end{array}$ & $\begin{array}{c}\text { Mais de } 10 \\
\text { anos }\end{array}$ & \multirow[t]{2}{*}{$p$} \\
\hline & & & & $\mathrm{n}(\%)$ acertos & n (\%) acertos & \\
\hline Cárie em menores de 1 ano & $8(61,5)$ & $21(61,8)$ & 1,000 & $6(42,9)$ & $9(75,0)$ & 0,209 \\
\hline Dentes de leite nascem com cáries & $2(15,4)$ & $10(29,4)$ & 0,464 & $7(50,0)$ & $4(33,3)$ & 0,646 \\
\hline Tratamento dentes de leite & $9(69,2)$ & $22(64,7)$ & 1,000 & $7(50,0)$ & $10(83,3)$ & 0,110 \\
\hline Primeira consulta com dentista & $12(92,3)$ & $30(88,2)$ & 1,000 & $10(71,4)$ & $12(100,0)$ & 0,100 \\
\hline Creme dental com flúor & $3(23,1)$ & $15(44,1)$ & 0,315 & $4(28,6)$ & $3(25,0)$ & 1,000 \\
\hline Fluorose & $2(15,4)$ & $15(44,1)$ & 0,094 & $4(28,6)$ & $6(50,0)$ & 0,422 \\
\hline Aleitamento materno prolongado & $0(0,0)$ & $3(8,8)$ & 0,550 & . & - & - \\
\hline Cárie e antibiótico & $1(7,7)$ & $11(32,4)$ & 0,136 & $4(28,6)$ & $4(33,3)$ & 1,000 \\
\hline Transmissibilidade bacteriana & $4(30,8)$ & $16(47,1)$ & 0,496 & $2(14,3)$ & $10(83,3)$ & $0,002^{*}$ \\
\hline Saúde bucal materna & $4(30,8)$ & $10(29,4)$ & 1,000 & $4(28,6)$ & $6(50,0)$ & 0,422 \\
\hline Sucos artificias são cariogênicos & $11(84,6)$ & $27(79,4)$ & 1,000 & $9(64,3)$ & $10(83,3)$ & 0,391 \\
\hline Fórmulas com açúcar & $1(7,7)$ & $6(17,6)$ & 0,655 & $2(14,3)$ & $0(0,0)$ & 0,483 \\
\hline Benefícios do aleitamento materno & $11(84,6)$ & $30(88,2)$ & 1,000 & $12(85,7)$ & $11(91,7)$ & 1,000 \\
\hline Adição de açúcar nas mamadeiras & $13(100,0)$ & $32(94,1)$ & 1,000 & $14(100,0)$ & $12(100,0)$ & \\
\hline Oriento uso de mamadeira & $13(100,0)$ & $31(91,2)$ & 0,550 & $14(100,0)$ & $11(91,7)$ & 0,462 \\
\hline Mamadeira noturna & $4(30,8)$ & $26(76,5)$ & $0,006^{*}$ & $7(50,0)$ & $10(83,3)$ & 0,110 \\
\hline Consumo de água após os seis meses & $10(76,9)$ & $30(88,2)$ & 0,377 & $13(92,9)$ & $10(83,3)$ & 0,580 \\
\hline Resistência do bebê à higiene bucal & $12(92,3)$ & $32(94,1)$ & 1,000 & $13(92,9)$ & $11(91,7)$ & 1,000 \\
\hline Conhecimentos e formação & $10(76,9)$ & $27(79,4)$ & 1,000 & $8(57,1)$ & $9(64,3)$ & 0,429 \\
\hline Saúde bucal durante a formação & $10(76,9)$ & $30(88,2)$ & 0,377 & $12(85,7)$ & $8(66,7)$ & 0,365 \\
\hline Espaços de Educação Permanente & $9(69,2)$ & $11(32,4)$ & $0,050 *$ & $8(57,1)$ & $4(33,3)$ & 0,413 \\
\hline Prática interdisciplinar & $12(92,3)$ & $27(79,4)$ & 0,413 & $11(78,6)$ & $8(66,7)$ & 0,665 \\
\hline Uso Protocolo da Criança & $7(53,8)$ & $27(79,4)$ & 0,142 & $13(92,9)$ & $11(91,7)$ & 1,000 \\
\hline Orientar sobre saúde bucal & $11(84,6)$ & $32(94,1)$ & 0,304 & $12(85,7)$ & $12(100,0)$ & 0,483 \\
\hline Somente equipe de saúde bucal orienta & $12(92,3)$ & $30(88,2)$ & 1,000 & $14(100,0)$ & $11(91,7)$ & 0,462 \\
\hline Frequência da limpeza da boca & $3(23,1)$ & $6(17,6)$ & 0,692 & $5(35,7)$ & $3(25,0)$ & 0,683 \\
\hline Como limpar boca sem dentes & $12(92,3)$ & $30(88,2)$ & 1,000 & $14(100,0)$ & $9(75,0)$ & 0,085 \\
\hline Como limpar a boca com dentes & $6(46,2)$ & $19(55,9)$ & 0,786 & $10(71,4)$ & $7(58,3)$ & 0,683 \\
\hline Qual pasta usar com 1 ano & $0(0,0)$ & $1(2,9)$ & 1,000 & $1(7,1)$ & $1(8,3)$ & 1,000 \\
\hline Quantidade de pasta para 1 ano & $6(46,2)$ & $20(58,8)$ & 0,650 & $8(57,1)$ & $9(75,0)$ & 0,429 \\
\hline Frequência ideal de consultas & $6(46,2)$ & $14(41,2)$ & 1,000 & $8(57,1)$ & $8(66,7)$ & 0,701 \\
\hline Nascimento dos primeiros dentes & $10(76,9)$ & $18(52,9)$ & 0,243 & $12(85,7)$ & $7(58,3)$ & 0,190 \\
\hline
\end{tabular}

${ }^{*} p<0,05$ teste $t$

Fonte: elaborado pelos autores com dados da pesquisa.

Em relação ao número de acertos para o grupo Conhecimentos profissionais sobre saúde bucal na primeira infância, a média dos médicos formados há menos de dez anos foi de 36,53 acertos (desvio de 12,04), e para os enfermeiros, 35,11 acertos (desvio de 19,10). Já os médicos formados há mais de dez anos apresentaram média de 45,58 acertos (desvio de 16,69), e os enfermeiros, 51,38 acertos (desvio de 13,60). No grupo Atitudes profissionais sobre saúde bucal na primeira infância, a média de acertos para os médicos formados há menos de dez anos foi 79,28 (desvio de 9,09), enquanto para os enfermeiros foi 82,96 (desvio de 12,50). Médicos com mais de dez anos de formados tiveram média de 82,57 acertos (desvio de 17,38), e enfermeiros, 82,05 acertos (desvio de 8,25). O grupo Práticas profissionais sobre saúde bucal na primeira infância apresentou como médias de acerto para os formados há menos de dez anos 47,25 (desvio de 12,21) para os médicos e 59,08 (desvio de 14,67) para os enfermeiros. Médicos com mais de dez anos de formado apresentaram média de 45,37 acertos 
(desvio de 9,09), já os enfermeiros obtiveram média de 52,38 acertos (desvio de 16,49). A Tabela 4 apresenta esses resultados, todos sem diferença estatisticamente significativa.

Tabela 4 - Média de acertos em cada grupo de questões por ano de formado e por formação profissional, SSC-GHC, Porto Alegre-RS, 2014

\begin{tabular}{|c|c|c|c|c|c|c|}
\hline \multirow{3}{*}{ Blocos questões } & \multicolumn{3}{|c|}{ Médicos } & \multicolumn{3}{|c|}{ Enfermeiros } \\
\hline & $\begin{array}{l}\text { Menos de } \\
10 \text { anos }\end{array}$ & $\begin{array}{l}\text { Mais de } \\
10 \text { anos }\end{array}$ & \multirow{2}{*}{$p$} & $\begin{array}{l}\text { Menos de } \\
10 \text { anos }\end{array}$ & $\begin{array}{l}\text { Mais de } \\
10 \text { anos }\end{array}$ & \multirow{2}{*}{$p$} \\
\hline & Média (DP) & Média (DP) & & Média (DP) & Média (DP) & \\
\hline $\begin{array}{l}\text { Conhecimentos profissionais sobre saúde } \\
\text { bucal na primeira infância }\end{array}$ & $36,53(12,04)$ & $45,58(16,69)$ & 0,082 & $35,11(19,10)$ & $51,38(13,60)$ & 0,222 \\
\hline $\begin{array}{l}\text { Atitudes profissionais sobre saúde bucal } \\
\text { na primeira infância }\end{array}$ & $79,28(9,09)$ & $82,57(17,38)$ & 0,552 & $82,96(12,50)$ & $82,05(8,25)$ & 0,831 \\
\hline $\begin{array}{l}\text { Práticas profissionais sobre saúde bucal } \\
\text { na primeira infância }\end{array}$ & $47,25(12,21)$ & $45,37(19,09)$ & 0,774 & $59,08(14,67)$ & $52,38(16,49)$ & 0,277 \\
\hline
\end{tabular}

Teste $\mathrm{t}$

Fonte: elaborado pelos autores com base nos dado da pesquisa.

\section{Discussão}

As doenças mais prevalentes nas crianças podem ser prevenidas ou controladas por meio da educação dos pais, ressaltando ser importante que a família, em especial a mãe, inclua em sua rotina hábitos adequados de higiene bucal, alimentação, e que evite hábitos de sucção deletérios do bebê.

A saúde bucal da criança pode e deve ser influenciada pelos membros da equipe de saúde, principalmente por médicos e enfermeiros, que estão em condições ideais para orientar os pais, visto que acompanham o desenvolvimento das crianças rotineiramente ${ }^{9}$, por meio de consultas de puericultura.

Em sistemas de saúde bem organizados, as informações relacionadas à alimentação e a hábitos de higiene bucal são tratadas de forma integrada por uma equipe multiprofissional ${ }^{6}$. A incorporação de conhecimentos de saúde bucal nas consultas de puericultura e pré-natal poderia resultar em maior integralidade do cuidado, aumento da autonomia dos cuidadores e um grande estímulo ao uso precoce de serviços odontológicos ${ }^{6}$.

Os resultados do presente estudo mostram ser possível a integração da saúde bucal em suas consultas de puericultura, realizando apenas algumas atualizações em seus conhecimentos, uma vez que na pergunta: "Considero viável fornecer orientações de saúde bucal para o cuidador do bebê durante as consultas de puericultura do primeiro ano?", $91,5 \%$ (43) dos médicos e 92,6\% (25) dos enfermeiros consideraram viável essa prática.

Apesar de os médicos terem conhecimento sobre etiologia e prevenção da cárie, eles sentem que seu nível de informação não é satisfatório, sugerindo um elevado grau de insegurança quanto à orientação que é dada aos pais, provavelmente devido à fragmentação e à pouca consistência das informações recebidas ${ }^{9}$. Ao contrário do estudo citado, $78,7 \%$ (37) dos médicos e $66,7 \%$ (18) dos enfermeiros participantes desse estudo relatam ter nível de informação satisfatório, entretanto, necessitam de atualizações sobre o tema. As questões que apontaram maior índice de erro e, portanto, necessidades de esclarecimentos foram as relacionadas à cárie dentária, presença de açúcar em fórmulas, frequência de higiene bucal e concentração de flúor adequada nos dentifrícios.

A maioria dos médicos respondeu satisfatoriamente às perguntas relacionadas à saúde bucal. Porém, apenas $18,8 \%$ dos pediatras tinham conhecimento adequado a respeito de todos os assuntos abordados no questionário ${ }^{10}$. Esse resultado demonstra que o conhecimento desses profissionais ainda se encontra aquém do esperado, considerando-se que as perguntas exigiam um conhecimento básico a respeito do assunto ${ }^{10}$.

No presente estudo, os profissionais com mais tempo de formado mostraram um pouco mais de conhecimento em relação à transmissibilidade de bactérias de mãe para filho. As bactérias são transmitidas da mãe para o filho, entretanto, estão presentes na microbiota bucal, que se mantém estável ao longo da vida do hospedeiro ${ }^{11}$.

Em uma visão geral, em sua maioria, os médicos e os enfermeiros participantes do presente estudo mostraram adequados conhecimentos, práticas e atitudes, contudo, apresentam falhas em alguns pontos, passíveis de serem corrigidas por meio de capacitações sobre o tema. Na questão referente aos espaços de educação permanente do SSC-GHC, a maioria dos profissionais, independente do tempo de formado, respondeu que as educações permanentes sobre puericultura não são suficientes para instrumentalizá-los em relação ao tema saúde bucal. Assim, espaços específicos de discussão sobre saúde bucal infantil podem ser potentes para instrumentalização da equipe multiprofissional na puericultura.

A questão referente ao uso do creme dental indicado pelos profissionais foi a que apresentou mais erros, apenas um médico e dois enfermeiros responderam corretamente. Tendo em vista que houve 
uma mudança na recomendação de dentifrício sem flúor ou com baixa concentração de flúor (500ppm) para dentifrício com alta concentração (1000ppm), urge que os profissionais sejam atualizados sobre as novas recomendações ${ }^{12,13}$.

A questão referente ao aleitamento materno prolongado associado à alimentação complementar, também apresentou baixo índice de acertos. Apenas três médicos $(6,4 \%)$ acertaram que esse fator pode contribuir para a ocorrência de cáries. Nenhum enfermeiro acertou a questão. $\mathrm{O}$ aleitamento materno prolongado e associado à alimentação complementar cariogênica pode favorecer o aparecimento da cárie precoce da infância ${ }^{14}$. Avaliaram-se crianças que receberam orientações alimentares baseadas nos dez passos da alimentação saudável, principalmente em relação a não introdução precoce da sacarose na dieta, e aquelas que não receberam essas orientações. Como resultado, o grupo que recebeu as informações apresentou menor incidência de cárie ${ }^{14}$.

As respostas da questão "Costumo desestimular o peito/mamadeira à noite a partir de um ano" mostraram grande índice de acertos, porém, os formados há mais tempo apresentaram maior percentual de acertos. Os profissionais reconhecem a importância da suspensão da mamada noturna para a prevenção da cárie dentária ${ }^{14}$.

A questão referente às fórmulas que contêm açúcar apresentou baixos índices de acertos. Sete médicos $(14,9 \%)$ e dois enfermeiros $(7,4 \%)$ acertaram que as fórmulas $\mathrm{NAN}^{\circledR}$, Ninho ${ }^{\circledR}$, Milupa ${ }^{\circledR}$ e Enfamil ${ }^{\circledR}$ não contêm açúcar. $\mathrm{O}$ baixo índice de acertos nessas questões é preocupante, pois são questões que abordam conhecimentos significativos para a prevenção da cárie dentária e deveriam ser de domínio de todos os profissionais de saúde, visto que são temas de fácil abordagem com os pais/responsáveis nas consultas de puericultura, e sua disseminação ajudaria a reduzir a prevalência de cárie precoce da infância.

A pergunta com resposta mais insatisfatória foi com relação à idade de encaminhamento ao dentista, sendo que 52,8\% não encaminhavam, ou recomendavam a visita tardiamente ${ }^{10}$. Para essa questão, no presente estudo, 89,4\% dos médicos e $85,2 \%$ dos enfermeiros responderam que a primeira consulta deve ocorrer no primeiro ano de vida, seguindo as recomendações do protocolo de Atenção à Saúde da Criança de 0 a 12 anos $(2014)^{4}$ do SSC-GHC, instituído como prática institucional e frequentemente revisado pelos profissionais. Os profissionais do serviço responderam que a erupção do primeiro dente ocorre por volta dos seis meses, o que indicaria o momento da consulta com o cirurgião-dentista.

A primeira consulta odontológica deveria servir como estratégia para reduzir a prevalência e a sequela de problemas bucais, bem como os custos com os serviços, porque crianças que visitam o cirurgião-dentista até o primeiro ano de vida apresentam menores chances de receber tratamentos odontoló$\operatorname{gicos}^{15}$.

Crianças que tem a primeira consulta no primeiro ano de vida têm mais consultas subsequentes para prevenção do que consultas para realizar tratamento restaurador ou de urgência ${ }^{16}$. Já as que têm a primeira consulta entre 2 e 3 anos, apresentam mais consultas para realizar tratamento restaurador e consultas de urgência. Isso pode ser explicado pela motivação dos pais que levaram as crianças no primeiro ano de vida com relação aos cuidados de saúde bucal do filho ${ }^{16}$.

No presente estudo, os resultados mostram que $50 \%$ dos profissionais recomendam a visita anual ao dentista, já a partir do primeiro ano de vida. Os demais recomendam semestralmente, e um profissional recomendou a visita bimestral.

Embora a efetividade do aconselhamento sobre saúde bucal não é suficientemente estudada, é recomendável que médicos e enfermeiros estimulem o aleitamento materno, desestimulem enfaticamente a ingestão de alimentos comprovadamente cariogênicos, principalmente açúcares refinados, e recomendem o início da escovação dentária a partir da erupção dos primeiros dentes, enfatizando a necessidade de supervisão até o final da idade escolar ${ }^{17}$.

O presente trabalho teve o intuito de incentivar que as informações referentes a hábitos de higiene bucal, de sucção deletéria (dedo e chupeta) e alimentar, sejam transmitidas nas consultas de puericultura realizadas até os seis meses pelo médico e/ ou enfermeiro, simplificando e facilitando a participação e compreensão por parte dos pais e/ou responsáveis, postergando, assim, a consulta odontológica específica do primeiro ano de vida do bebê para o período de seis a doze meses de idade.

\section{Conclusão}

Os resultados obtidos com este estudo permitem concluir que tanto os médicos como os enfermeiros do Serviço de Saúde Comunitária do GHC têm bons conhecimentos e práticas referentes à saúde bucal na puericultura. Contudo, foi apontada a necessidade de atualizar os profissionais sobre as mudanças referentes ao tema, pois apresentaram assuntos com inadequados conhecimentos e condutas, com ações periódicas de educação permanente sobre saúde bucal infantil visando à qualificação e à atualização dos profissionais. Essas intervenções ficariam sob a responsabilidade das equipes de saúde bucal inseridas nas equipes, tendo em vista que isso pode qualificar o trabalho interdisciplinar, melhorando o cuidado integral aos pacientes por todos os profissionais de saúde que compõem as equipes do SSC-GHC. A partir disso, acredita-se que os profissionais médicos e enfermeiros possam assumir as orientações sobre saúde bucal nos primeiros seis meses de vida da criança, deixando a consulta com 
o cirurgião-dentista para após o nascimento do primeiro dente, tornando-a mais interessante para a mãe/cuidador.

\section{Agradecimentos}

Agradeçemos aos colegas Maitê Bello Jotz, pelo apoio estatístico, e Leonardo Fernandes, pela ajuda na coleta de dados.

\section{Abstract}

Objective: to investigate oral health knowledge, attitudes, and practices of childcare doctors and nurses - employees and residents from the Serviço de Saúde Comunitária do Grupo Hospitalar Conceição (SSC-GHC). Subjects and method: Application of a closed questionnaire, with 32 multiple-choice questions, developed by the researchers to assess oral health knowledge, attitudes, and practices (KAP) of childcare doctors and nurses (employees and residents) from eleven of the twelve healthcare units of the CHS-HGC. The purposive sample was composed by 47 doctors and 27 nurses. Data were tabulated and analyzed with the SPSS software, through the chi-square test and test, at a statistical significance level of $p<0.05$. Results: The results obtained show that there is little significant difference among the knowledge, attitudes, and practices of doctors and nurses from the CHS-HGC, including the time of professional training/practice. Conclusion: Many doctors and nurses are still unfamiliar with some aspects of oral health in childcare, thus requiring permanent education on the topic.

Keywords: Oral Health. Childcare. Primary Health Care. Family Doctors. Family Health Nurses.

\section{Referências}

1. Costa ICC. Atenção odontológica à gestante na triangulação médico-dentista-paciente. Araçatuba/SP [Tese de doutorado em Odontologia Preventiva e Social]. Universidade Estadual Paulista Júlio de Mesquita Filho; São Paulo; 2000.

2. Finkler M, Oleiniski DMB, Ramos FRS. Saúde bucal materno-infantil: um estudo de representações sociais com gestantes. Texto \& Contexto Enferm 2014; 13(3):360-8.

3. Marangon CMLV, organizadora. Diretriz de atenção à saúde da criança. Curitiba: Secretaria Municipal da Saúde; 2012.

4. Lenz ML, Flores R, organizadores. Atenção à saúde da criança de 0 a 12 anos. Porto Alegre: Grupo Hospitalar Conceição; 2014.

5. Ministério da Saúde (Brasil). Secretaria de Atenção à Saúde. Departamento de Atenção Básica. Cadernos de atenção básica: saúde bucal. Brasília, DF: Ministério da Saúde; 2008.

6. Camargo MBJ, Barros AJD, Frazão P, Matijasevich A, Santos IS, Peres MA, et al. Preditores da realização de consultas odontológicas de rotina e por problema em pré-escolares. Rev Saude Publica 2012; 46(1):87-97.

7. Luz PB. Cárie precoce da infância: influência de variáveis sociais, psicológicas e comportamentais. [Tese de doutorado em Odontopediatria]. Porto Alegre: Universidade Federal do Rio Grande do Sul; 2014.
8. Soares IMV, Silva AMRB, Moura LFAD, Lima MDM, Netto OBS, Moura MS. Conduct of pediatricians in relation to the oral health of children. Rev Odontol Unesp 2013; 42(4):266-72.

9. Freire MCM, Macêdo RA, Silva WH. Conhecimentos, atitudes e práticas dos médicos pediatras em relação à saúde bucal. Pesq Odontol Bras 2000; 14(1):39-45.

10. Ferro RL, Bonow MLM, Romano AR, Torriani DD. Integração entre pediatria e odontopediatria: uma abordagem transdisciplinar na saúde bucal infantil. Rev AMRIGS 2011; 55(1):31-6

11. Rosa RT, Gonçalves RG, Rosa EAR. Transmissibilidade de estreptococos cariogênicos: uma atualização conceitual. Rev Clin Pesq Odontol 2005; 1(4):25-37.

12. Brasil. Ministério da Saúde. Secretaria de Atenção à Saúde. Guia de recomendações para o uso de fluoretos no Brasil. Brasília, DF: Ministério da Saúde; 2009.

13. Hugo FN, Rosing CK, Araujo FB. Consenso do Simpósio sobre Riscos e Benefícios de Dentifrícios Fluoretados na Primeira Infância. Rev Fac Odontol Porto Alegre 2012; 53(3):41-2.

14. Feldens CA, Vítolo MR, Drachler ML. A randomized trial of the effectiveness of home visits in preventing early childhood caries. Community Dent Oral Epidemiol 2007; 35:215-23.

15. Lee JY, Bouwens TJ, Savage MF, Vann WF. Examining the cost-effectiveness of early dental visits. Pediatr Dent 2006; 28(2):102-5.

16. Savage MF, Lee JY, Kotch JB, Vann WF. Early preventive dental visits: effects on subsequent utilization and costs. Pediatrics 2004; 114:418-23.

17. Blank, D. A puericultura hoje: um enfoque apoiado em evidências. J Pediatr 2003; 79(1):13-22.

Endereço para correspondência:

Mariana Loch dos Reis

Av. Francisco Trein, 596, Bairro Cristo Redentor 91350-200 Porto Alegre, Rio Grande do Sul, Brasil Telefone: 5133626727

E-mail: mari_loch@hotmail.com

Recebido: 04/02/15. Aceito: 18/06/15. 